\title{
Monomer Unit Sequence Distribution in Partly-Epoxidized trans-1,4-Polyisoprene
}

\author{
Osamu Hayashi, Tooru TAKahashi, Hideo KURIHARA, \\ and Haruo UENO \\ Polymer Research Laboratory, Ube Industries, Ltd., \\ 8-1, Minami Kaigan, Goi, Ichihara 290, Japan.
}

(Received June 21, 1980)

\begin{abstract}
The monomer unit sequence distribution in partly epoxidized trans-1,4polyisoprene was determined by the ${ }^{13} \mathrm{C}$ NMR spectrometry available. Epoxidation of polymer was carried out by peracid prepared in situ from hydrogen peroxide and a small amount of formic acid, and the epoxy content in the modified polymer was determined by ${ }^{1} \mathrm{H}$ NMR. The ${ }^{13} \mathrm{C}$ NMR spectra of the partly epoxidized trans-1,4-polyisoprene exhibited new signals both in the olefinic and aliphatic carbon regions, in addition to the signals due to the original trans-1,4-polyisoprene. Each signal, except for the methyl carbon signals, was interpreted in terms of the dyad or triad of trans-1,4 and epoxidized units, taking into consideration the results from the signal assignments made by offresonance decoupling techniques and lanthanide shift reagent experiments. The monomer unit sequence distribution in partly epoxidized trans-1,4-polyisoprene determined by ${ }^{13} \mathrm{C} N \mathrm{NR}$ agreed very closely with that calculated on the basis of the random distribution of trans $-1,4$ and epoxidized isoprene units. These results suggest that the site of the epoxy group formed is not affected by such groups previously formed in polyisoprene.
\end{abstract}

KEY WORDS Epoxidation / trans-1,4-Polyisoprene $/{ }^{13} \mathrm{C}$ NMR / Sequence

Distribution / Olefinic Carbon/ Off-Resonance Decoupling / Shift Reagent /

Random /

Carbon-13 nuclear magnetic resonance spectroscopy has been intensively utilized in the study of the monomer sequence distribution of various polydienes. ${ }^{1-9}$ Some reports have been published on the squence distribution of 3,4 and 1,4 units or cis-1,4and trans-1,4-isoprene units in polyisoprenes. ${ }^{10-15}$ As for chemically-modified polymers, however, few ${ }^{13} \mathrm{C}$ NMR investigations have been made both on the reaction site and the sequence distribution of modified and unmodified units. ${ }^{16-18}$ Gemmer and Golub $^{19}$ reported the ${ }^{13} \mathrm{C}$ NMR spectra of partly epoxidized 1,4-polyisoprenes and 1,4-polybutadienes, and interpreted the prominent signals in terms of the dyad of $c i s-1,4$ units and epoxidized units, though the signal assignments were not discussed in detail.

Previously, we studied the epoxidation of polybutadiene by organic peracid, and determined the monomer unit sequence distribution in the partly epoxidized cis-1,4-polybutadiene by proton- decoupled ${ }^{13} \mathrm{C}$ NMR spectra. ${ }^{20-21}$ It is of interest that the relative intensities of the carbon signals in the polymers of different epoxy content were almost identical with those calculated on the basis of the random distribution of cis-1,4 and epoxidized butadiene units. Our attention was then directed to the study of partly-epoxidized polyisoprene by ${ }^{13} \mathrm{C}$ NMR. The ${ }^{13} \mathrm{C}$ NMR spectrum of partlyepoxidized cis-1,4-polyisoprene exhibited a very complicated resonance pattern due to the overlapping of methylene and methyl carbon signals. ${ }^{19,22}$

In this paper, we attempt to make an assignment of the ${ }^{13} \mathrm{C}$ NMR signals of partly-epoxidized trans1,4-polyisoprene in terms of the triad of trans-1,4 and epoxidized units, in contrast to the work done by Gemmer et al. and further the sequence distribution of the units and the reaction site is discussed. 


\section{EXPERIMENTAL}

\section{Epoxidation}

A natural trans-1,4-polyisoprene, gutta percha, consisting exclusively of the trans-1,4 structure, ${ }^{1}$ was used in this study and was purified by repeated precipitation from a chloroform solution with methanol. Epoxidation was carried out in situ by peroxy formic acid as follows: a solution of trans1,4-polyisoprene $(3.41 \mathrm{~g} ; 0.05 \mathrm{~mol}$ monomer unit) and 2,6-di- $t$-butyl-p-cresol $(0.1 \mathrm{~g})$ as a polymer stabilizer in $200 \mathrm{ml}$ of benzene was heated to $35^{\circ} \mathrm{C}$ and mixed with $60 \mathrm{mmol}$ of $30 \%$ aq hydrogen peroxide and a small amount of formic acid (15 mmol). The solution was stirred at the same temperature for 1 to $10 \mathrm{~h}$. The epoxidized polymer was obtained by pouring the reaction mixture into methanol to precipitate the product.

\section{${ }^{1} H$ and ${ }^{13} C N M R$ experiments}

${ }^{1} \mathrm{H}$ NMR spectra were obtained at room temperature on $\mathrm{ca}$. $5 \%$ solution of polymers in $\mathrm{CDCl}_{3}$, using a JEOL C-60 HL spectrometer. Chemical shifts of the signals were measured in ppm relative to tetramethylsilane (TMS).

The ${ }^{13} \mathrm{C}$ NMR spectra were obtained at 25.1 $\mathrm{MHz}$, using a JEOL JNM-PS/PFT 100 spectrometer equipped with a Fourier transform accessory. The ${ }^{13} \mathrm{C}$ NMR spectrum was measured at $50^{\circ} \mathrm{C}$ in $\mathrm{CDCl}_{3}$ (approximately $8 \mathrm{w} / \mathrm{v} \%$ ), under the condition of a $13.0 \mu \mathrm{s}\left(45^{\circ}\right)$ pulse width, using TMS as the internal standard. The spectra were recorded as proton noise-decoupling with multiple scans at a pulse-repetition time of $3.0 \mathrm{~s}$ or as off-resonance decoupling at a pulse-repetition time of $1.0 \mathrm{~s}$. The relative intensities of the signals in the ${ }^{1} \mathrm{H}$ NMR and ${ }^{13} \mathrm{C}$ NMR spectra were determined by cutting out and then weighing each peak area in the Xerox copies of the spectra. When the cutting out of peak areas was not practicable, signal intensities were taken to be proportional to signal heights.

\section{RESULTS AND DISCUSSION}

It is known that the epoxidation of unsaturated bonds in a polydiene with organic peracid does not degradate the polymer ${ }^{23}$ but is accompanied by a ring-opening reaction, ${ }^{24-27}$ (eq 1,2 , and 3),

$$
\mathrm{RCO}_{2} \mathrm{H}+\mathrm{H}_{2} \mathrm{O}_{2} \rightleftharpoons \mathrm{RCO}_{3} \mathrm{H}+\mathrm{H}_{2} \mathrm{O}
$$
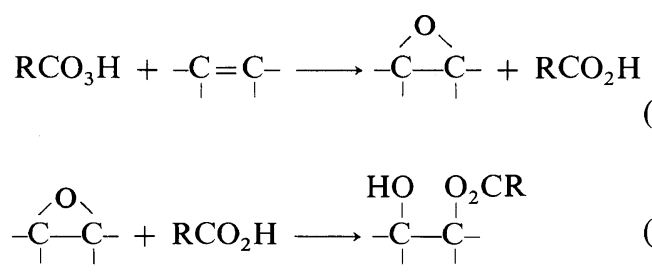

We have already reported the epoxidation of polybutadiene under mild reaction conditions, such as low temperature and using a small amount of formic acid, enabling the reaction to be easily carried out with very few additional reactions. ${ }^{20,21}$ In the epoxidation of trans-1,4-polyisoprene, the same reaction conditions as mentioned above for polybutadiene were employed.

The ${ }^{1} \mathrm{H}$ NMR spectrum of the partly-epoxidized trans-1,4-polyisoprene indicates that the signals are assignable to the protons of the unmodified monomer unit and to the epoxidized unit produced in the reaction, and confirms that the ring-opening

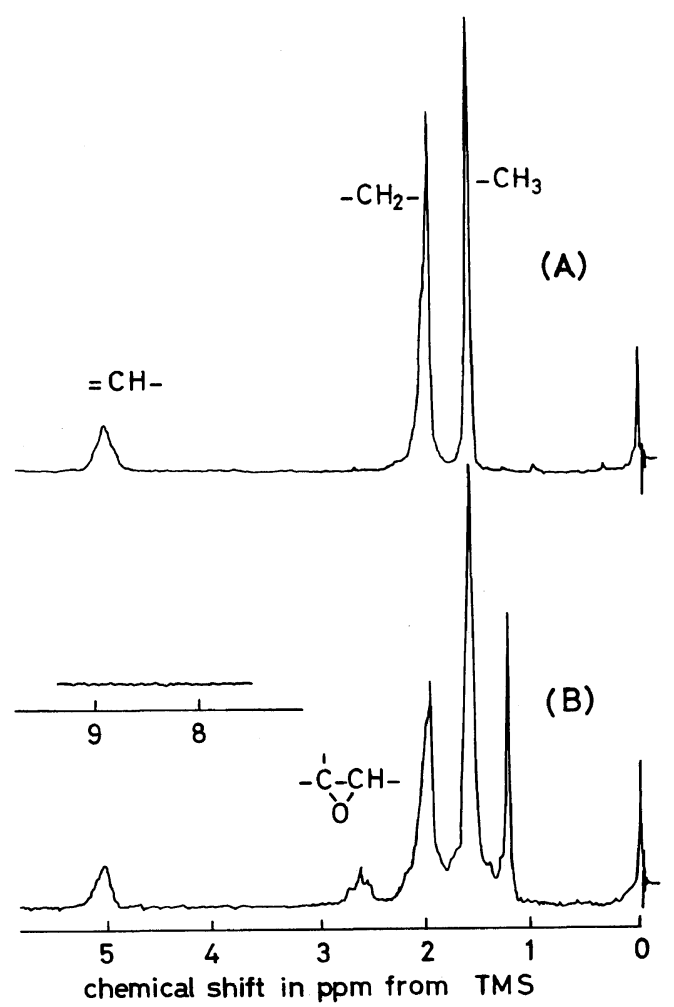

Figure 1. ${ }^{1} \mathrm{H}$ NMR spectra of (A) trans-1,4polyisoprene and (B) partly epoxidized polymer; degree of epoxidation, $39 \%$. 


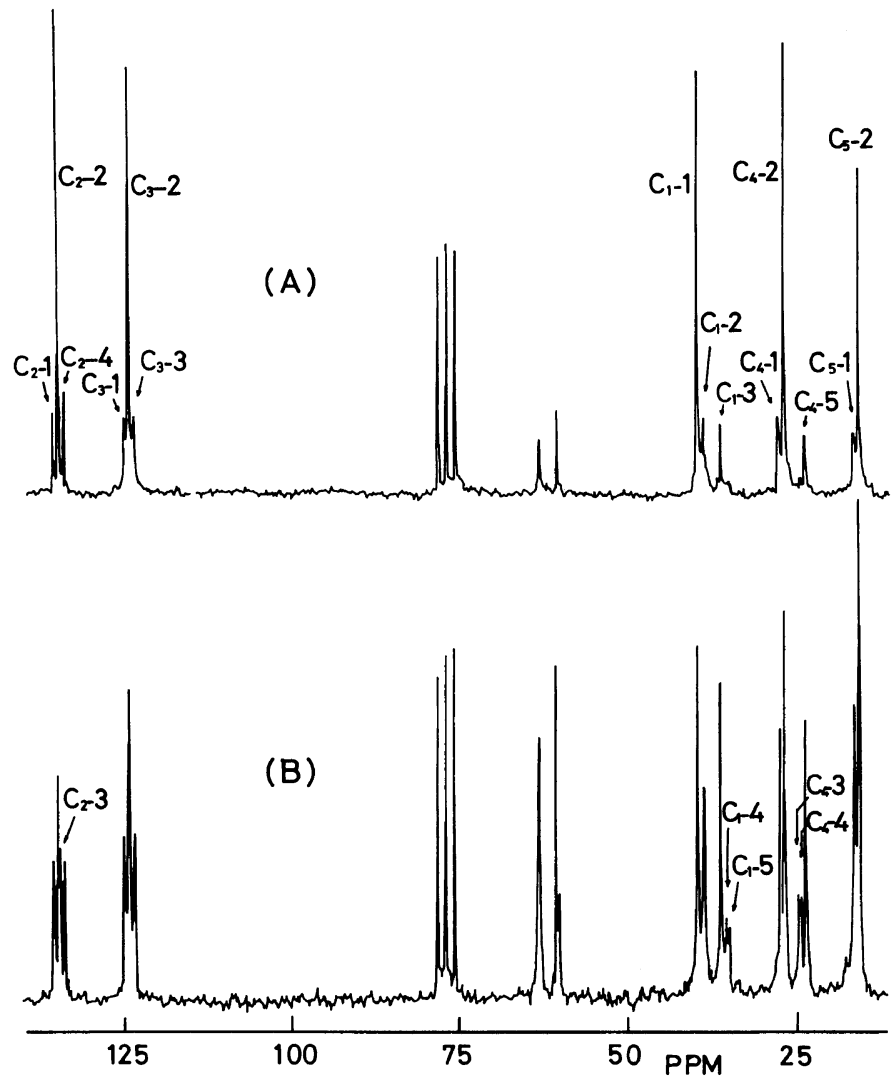

Figure 2. Proton-decoupled ${ }^{13} \mathrm{C}$ NMR spectra of partly-epoxidized trans-1,4-polyisoprene. Repetition time of $45^{\circ}$ pulses is $3.0 \mathrm{~s}$. Chemical shift scale in ppm from TMS. Degree of epoxidation (\%): A, 17; B, 39 . The signals are assigned in Tables I and II.

reaction is negligible since no signals appeared in the region of the formyloxy proton around $8 \mathrm{ppm}$. The signals at 5.08 and $2.68 \mathrm{ppm}$, assigned to the olefinic and epoxy methine protons, were used for calculating the epoxy content of the polymer by eq 4 , (Figure 1),

Degree of epoxidation

$$
=\frac{\text { Peak area at } 2.68 \mathrm{ppm}}{\text { Peak area at } 5.08 \text { and } 2.68 \mathrm{ppm}}
$$

The ${ }^{13} \mathrm{C}$ NMR spectra of the partly-epoxidized trans-1,4-polyisoprenes containing various amounts of epoxidized units in the polymer are shown in Figures 2-4. For conveniently discussing the procedure for making assignment of signals, the signals were labeled as shown in the Figures. The triplet at $c a .77 \mathrm{ppm}$ is due to $\mathrm{CDCl}_{3}$.
The five signals at $134.90\left(\mathrm{C}_{2}-2\right), 124.37\left(\mathrm{C}_{3}-2\right)$, $39.80\left(\mathrm{C}_{1}-1\right), 26.87\left(\mathrm{C}_{4}-2\right)$, and $16.08\left(\mathrm{C}_{5}-2\right)$ correspond to carbons of trans-1,4-polyisoprene, and were assigned to the $\mathrm{C}_{2}, \mathrm{C}_{3}, \mathrm{C}_{1}, \mathrm{C}_{4}$, and $\mathrm{C}_{5}$ carbons of trans-1,4-polyisoprene in the order of increasing magnetic field. ${ }^{1}$ The symbols for the carbon atoms are denoted as follows:

$$
\begin{array}{cccc}
-\mathrm{CH}_{2}-\mathrm{C}\left(\mathrm{CH}_{3}\right) & =\mathrm{CH}-\mathrm{CH}_{2}- \\
1 & 2 & 5 & 3
\end{array}
$$

With the epoxidation of the reactant polymer, the 1,4-unit is converted to the structure II:

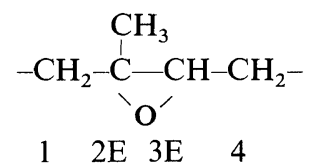

II

Unlike the simple ${ }^{13} \mathrm{C}$ NMR spectra of partly- 


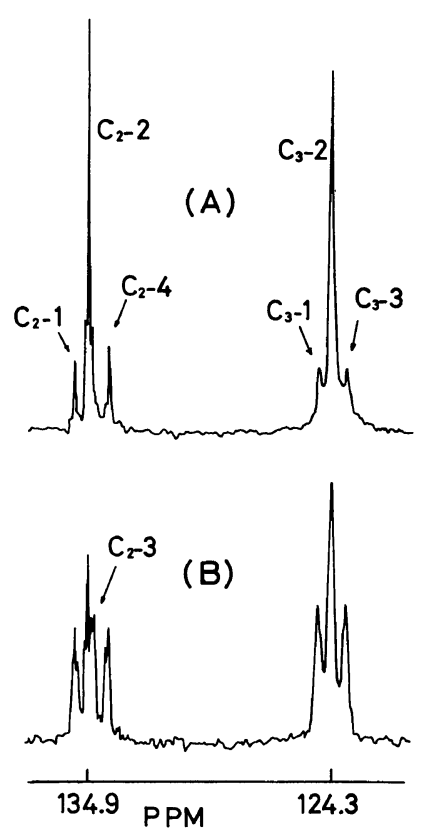

Figure 3. Carbon-13 NMR expanded spectra of the olefinic carbon regions of partly epoxidized trans-1,4polyisoprenes. The samples used are the same as in Figure 2. Degree of epoxidation ( $\%)$ : A, 17; B, 39. The signals are assigned in Table I.

epoxidized 1,4-polybutadiene, ${ }^{21}$ more complicated signals could be observed in the ${ }^{13} \mathrm{C}$ NMR spectra of partly-epoxidized trans-1,4-polyisoprene. The spectra exhibited many peaks of lesser intensity than those attributable to the unepoxidized isoprene units. Their intensities increase with an increase in the epoxy units in the polymer. This fact suggests that the peaks $\left(C_{2}-1, C_{2}-3, C_{2}-4\right)$, $\left(C_{3}-1, C_{3}-3\right),\left(C_{1}-2-C_{1}-5\right),\left(C_{4}-1, C_{4}-3-C_{4}-5\right)$, and $\mathrm{C}_{5}-1$ arise from carbons of epoxidized isoprene units or from carbons of unepoxidized isoprene units affected by adjacent epoxidized units in the polymer.

Similar notations in ref 21 are used in this paper. The possible triad sequences are, T (T) T, E (T) T, T (T) E, E (TE. T E T, E (E) T, T E E, and $\mathrm{E}$ (E) E, where $\mathrm{T}$ represents a trans-1,4-isoprene unit (I) and $\mathrm{E}$ represents an epoxidized isoprene unit (II). Thus $\mathrm{T}$ (E) $\mathrm{T}$ indicates an epoxidized isoprene unit adjacent to trans-1,4-isoprene units. Similarly $\mathrm{T}^{1}$ (E) $\mathrm{T}$ represents a $\mathrm{C}_{1}$ carbon in the $\mathrm{T}$ (E) $\mathrm{T}$ triad. Also, ${ }^{1}$ ( $),{ }^{2}$ (T), (T) ${ }^{3},\left(\mathrm{~T}^{4},{ }^{5} \mathrm{~T},{ }^{1}\right.$ (E),${ }^{2}$ (E), (E) ${ }^{3}$, (E) ${ }^{4}$ and ${ }^{5}$ (E) represent the $C_{1}, C_{2}, C_{3}, C_{4}, C_{5}$ carbons

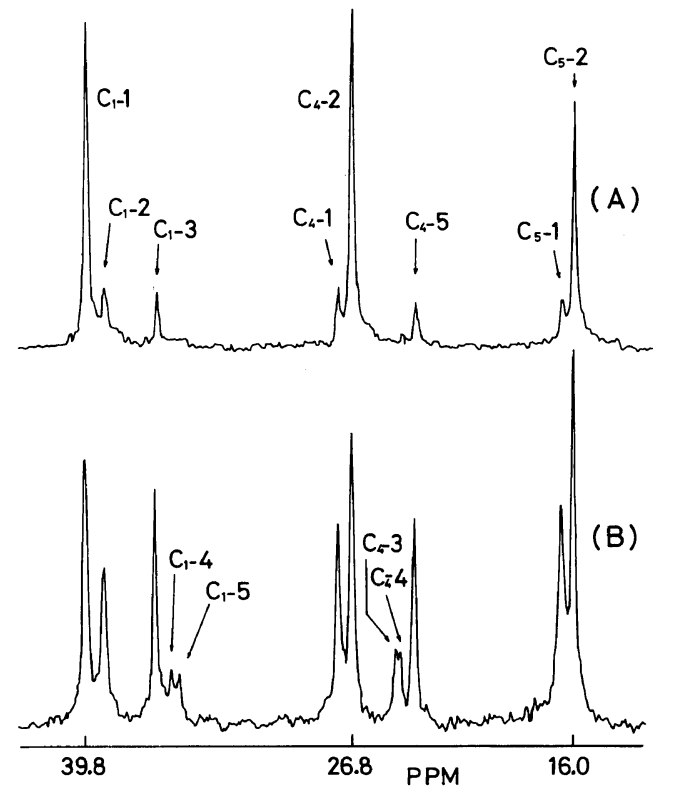

Figure 4. Carbon-13 NMR expanded spectra of the methylene and the methyl carbon regions of partlyepoxidized trans-1,4-polyisoprenes. The samples used are the same as in Figure 2. Degree of epoxidation (\%): A, 17; B, 39. The signals are assigned in Table II.

in an unreacted trans-1,4-isoprene unit and in an epoxidized unit respectively. In referring to the relative position of the carbons in a unit, we use the numbers 1,2 , and 5 on the left shoulder and 3,4 on the right shoulder of $\mathrm{T}$ or $\mathrm{E}$.

In the present study, we assumed only the trans configuration for the epoxy group in the polymer, since Swern and his coworkers ${ }^{28-30}$ proved that the epoxidation of alkenes results in syn addition, and consequently, the stereochemistry of the alkenes is maintained in the product.

\section{Off-resonance Decoupling}

The assignment of the ${ }^{13} \mathrm{C}$ NMR signals to quaternary, tertiary, and methyl carbons was confirmed by the off-resonance decoupling method. The ${ }^{13} \mathrm{C}$ NMR spectrum in Figure 5 (A) shows the off-resonance decoupled signals of the epoxidized trans-1,4-polyisoprene of $48 \%$ epoxy content. Figure 5 (B) shows the proton-decoupled ${ }^{13} \mathrm{C}$ NMR spectrum of the same polymer. The two upfield peaks $\mathrm{C}_{5}-1$ and $\mathrm{C}_{5}-2$ near 16 ppm can be readily assigned to the branching methyl carbons, since 


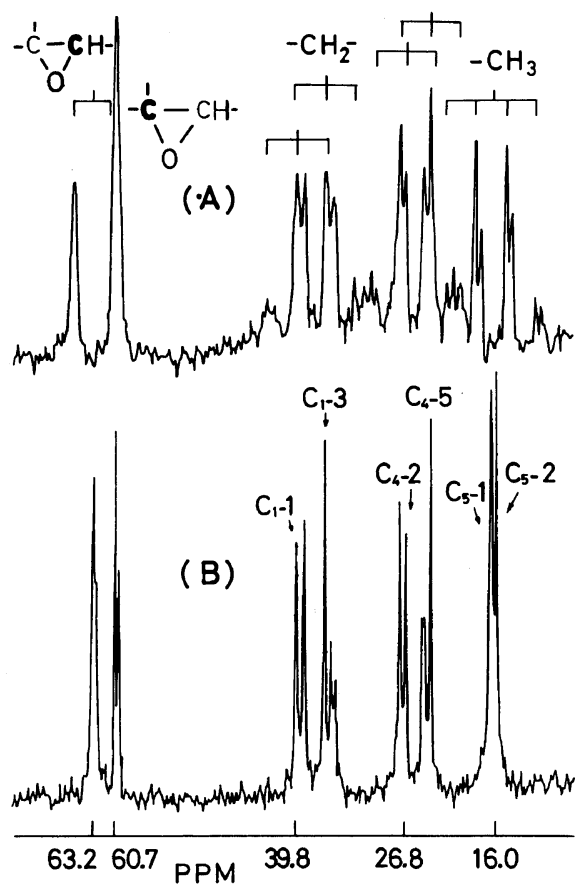

Figure 5. Carbon-13 NMR spectra of the aliphatic and the epoxy carbon regions of partly-epoxidized polyisoprene. Degree of epoxidation $48 \%$. (A) off-resonance decoupling NMR spectrum; repetition time $1.0 \mathrm{~s}, 10,000$ scans. (B) proton-decoupled NMR spectrum; repetition time, $3.0 \mathrm{~s}, 3,000$ scans. Chemical shift scale in ppm from TMS.

these peaks split into quartets by off-resonance decoupling, indicating the presence of three directlybonded protons. The signals at 60.65 and $60.26 \mathrm{ppm}$ for which large proton couplings are absent, can be assigned to the epoxy ring carbon $\left(\mathrm{C}_{2 \mathrm{E}}\right)$ which has a methyl group, because this carbons remained singlet in off-resonance decoupling in the absence of a directly-bonded proton. The signal at $63.21 \mathrm{ppm}$ $\left(C_{3 E}\right)$ however, split into doublets and one of these overlapped with the signal of $\mathrm{C}_{2 \mathrm{E}}$. The intriguing order of the chemical shifts of $\mathrm{C}_{2 \mathrm{E}}$ and $\mathrm{C}_{3 \mathrm{E}}$, which is opposite to that of the corresponding olefinic $\mathrm{C}_{2}$ and $\mathrm{C}_{3}$, was reported by Gemmer and Golub. ${ }^{19}$

\section{Lanthanide Shift Reagent Experiments}

The remaining signals in the spectrum were assigned on the basis of the results of lanthanide shift reagent (LSR) experiments. The polymer in Figure 2 (A) contains small amounts of epoxidized units. Figures 6 and 7 indicate variations in the

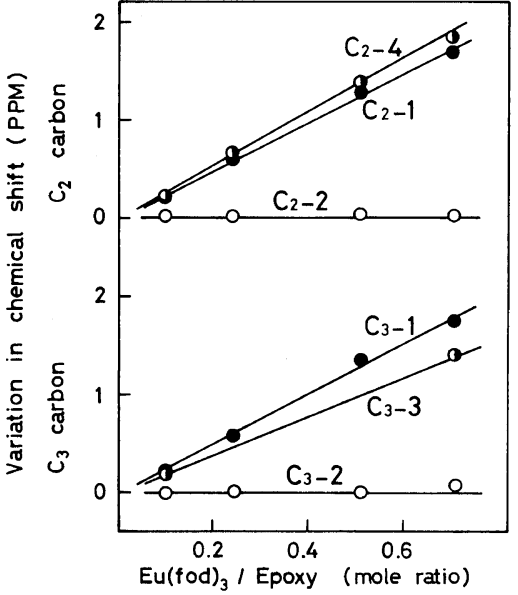

Figure 6. Variation in chemical shift of different olefinic carbons in partly-epoxidized trans-1,4polyisoprene with increasing concentration of $\mathrm{Eu}(\mathrm{fod})_{3}$. Degree of epoxidation, $17 \%$. The symbols are the same as in Figure 3.

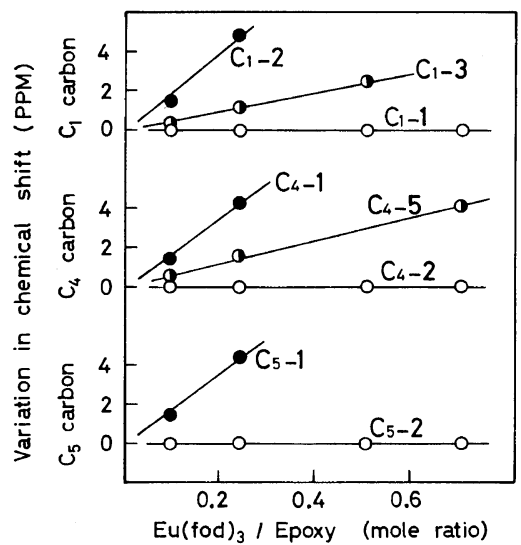

Figure 7. Variation in the chemical shift of different methylene and methyl carbons in partly-epoxidized trans-1,4-polyisoprene with increasing concentration of $\mathrm{Eu}(\mathrm{fod})_{3}$. Degree of epoxidation, $17 \%$. Symbols are the same as in Figure 4.

carbon chemical shifts of the epoxidized polymer with the addition of tris $(6,6,7,7,8,8,8$-heptafluoro2,2-dimethyl-3,5-octanedionate) europium (III) $\left[\mathrm{Eu}(\mathrm{fod})_{3}\right]_{\text {to }}$ the NMR sample. The chemical shift was measured as a function of the added $\mathrm{Eu}(\mathrm{fod})_{3}$ concentration to determine how close the carbons are to the epoxy moieties; ${ }^{31,32}$ the steeper the slope, the closer the associated carbon to the epoxy moiety. These LSR experiments helped in the 
O. Hayashi, T. Takahashi, H. Kurihara, and H. Ueno

Table I. Signal assignments of olefinic carbons

\begin{tabular}{|c|c|c|}
\hline \multirow{2}{*}{ Signal } & Chemical shift & \multirow{2}{*}{ Assignments $^{\mathrm{a}}$} \\
\hline & ppm & \\
\hline \multicolumn{3}{|c|}{$\mathrm{C}_{2}$ carbon } \\
\hline $\mathrm{C}_{2}-1$ & 135.48 & $\mathrm{~T}^{2} \mathrm{~T} \mathrm{E}$ \\
\hline $\mathrm{C}_{2}-2$ & 134.90 & $\mathrm{~T}^{2} \mathrm{~T} \mathrm{~T}$ \\
\hline $\mathrm{C}_{2}-3$ & 134.78 & $\mathrm{E}^{2} \mathrm{~T} \mathrm{E}$ \\
\hline $\mathrm{C}_{2}-4$ & 134.04 & $\mathrm{E}^{2} \mathrm{~T} \mathrm{~T}$ \\
\hline \multicolumn{3}{|c|}{$\mathrm{C}_{3}$ carbon } \\
\hline $\mathrm{C}_{3}-1$ & 124.92 & $\mathrm{~T}\left(\mathrm{~T}^{3} \mathrm{E}\right.$ \\
\hline $\mathrm{C}_{3}-2$ & 124.30 & $\mathrm{~T}\left(\mathrm{~T}{ }^{3} \mathrm{~T}, \mathrm{E}\left(\mathrm{T}^{3} \mathrm{E}\right.\right.$ \\
\hline $\mathrm{C}_{3}-3$ & 123.68 & $\mathrm{E}\left(\mathrm{T}^{3} \mathrm{~T}\right.$ \\
\hline
\end{tabular}

a Symbols for the carbons are as follows: for T (trans-1,4 unit), $-\mathrm{CH}_{2}-\stackrel{\mathrm{CH}_{3}}{\mathrm{C}}=\mathrm{CH}-\mathrm{CH}_{2}-$ and for $\mathrm{E}$ (epoxidized unit), $-\mathrm{CH}_{2}-\stackrel{\stackrel{\mathrm{l}}{\mathrm{C}}-\underset{\mathrm{O}}{\mathrm{C}}-\mathrm{C}}{\mathrm{C}} \mathrm{H}-\mathrm{CH}_{2}-$

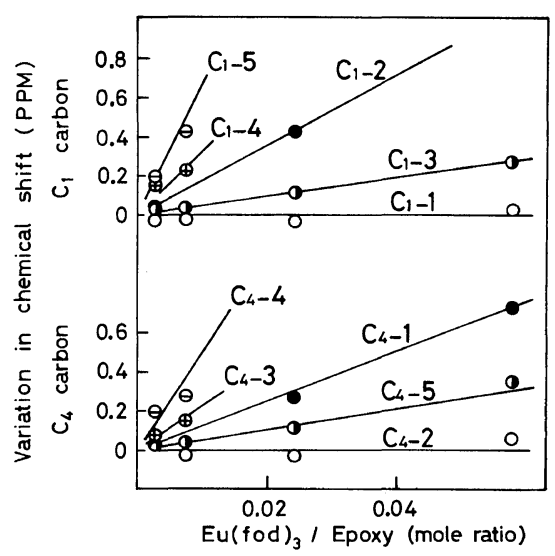

Figure 8. Variation in chemical shift of different methylene carbons in partly epoxidized trans-1,4polyisoprene with increasing concentration of $\mathrm{Eu}(\mathrm{fod})_{3}$. Degree of epoxidation, $39 \%$. The symbols are the same as in Figure 4.

assignment of puzzling signals.

The signals of the olefinic carbons $\left(\mathrm{C}_{2}\right.$ and $\left.\mathrm{C}_{3}\right)$ were assigned to one of the four $\mathrm{T}$ centered triad sequences of trans-1,4 and epoxidized units shown in Table I, based on the results derived from Figure 6. This assignment patttern for olefinic carbons was previously observed for partly epoxidized cis-1,4-
Table II. Signal assignment for methylene and methyl carbons

\begin{tabular}{|c|c|c|}
\hline \multirow{2}{*}{ Signal } & Chemical shift & \multirow{2}{*}{ Assignments $^{\mathrm{a}}$} \\
\hline & ppm & \\
\hline \multicolumn{3}{|c|}{$\mathrm{C}_{1}$ carbon } \\
\hline $\mathrm{C}_{1}-1$ & 39.80 & $\mathrm{~T}^{1} \mathrm{~T} \mathrm{~T}, \mathrm{~T}^{1} \mathrm{~T} \mathrm{E}$ \\
\hline $\mathrm{C}_{1}-2$ & 38.87 & $\mathrm{~T}^{1}$ (E) $\mathrm{T}, \mathrm{E}^{1}$ (E) $\mathrm{E}$ \\
\hline$C_{1}-3$ & 36.38 & $\mathrm{E}^{1} \mathrm{~T} \mathrm{~T}, \mathrm{E}^{1}$ (T) $\mathrm{E}$ \\
\hline $\mathrm{C}_{1}-4$ & 35.65 & $\mathrm{~T}^{1}$ (E) $\mathrm{E}$ \\
\hline$C_{1}-5$ & 35.30 & $\mathrm{E}^{1}$ (E) $\mathrm{T}$ \\
\hline \multicolumn{3}{|c|}{$\mathrm{C}_{4}$ carbon } \\
\hline $\mathrm{C}_{4}-1$ & 27.53 & $\mathrm{~T}$ (E) ${ }^{4} \mathrm{~T}, \mathrm{E}$ (E) ${ }^{4} \mathrm{E}$ \\
\hline $\mathrm{C}_{4}-2$ & 26.83 & $\mathrm{~T}\left(\mathrm{~T}{ }^{4} \mathrm{~T}, \mathrm{E}\left(\mathrm{T}^{4} \mathrm{~T}\right.\right.$ \\
\hline $\mathrm{C}_{4}-3$ & 24.70 & $\mathrm{E}(\mathrm{E})^{4} \mathrm{~T}$ \\
\hline $\mathrm{C}_{4}-4$ & 24.58 & $\mathrm{~T}$ (E) ${ }^{4} \mathrm{E}$ \\
\hline $\mathrm{C}_{4}-5$ & 23.80 & $\mathrm{~T}\left(\mathrm{~T}{ }^{4} \mathrm{E}, \mathrm{E}(\mathrm{T})^{4} \mathrm{E}\right.$ \\
\hline \multicolumn{3}{|c|}{$\mathrm{C}_{5}$ carbon } \\
\hline $\mathrm{C}_{5}-1$ & 16.70 & 5 (E) \\
\hline $\mathrm{C}_{5}-2$ & 16.08 & ${ }^{5} \mathrm{~T}$ \\
\hline
\end{tabular}

a Symbols for the carbons are as follows: for T (trans-1,4

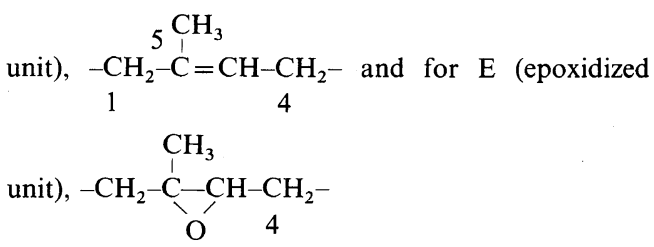

polybutadiene. ${ }^{21}$ Since the chemical shift variations in $\mathrm{C}_{2}-1$ and $\mathrm{C}_{2}-4$ are not very different (Figure 6), no accurate assignment can be expected presently. An attempt to separate the signal assignable to $\mathrm{E}\left(\mathrm{T}^{3} \mathrm{E}\right.$ from the $\mathrm{C}_{3}-2$ signal consisting mainly of $T \mathrm{~T}^{3} \mathrm{~T}$ proved unsuccessful even in LSR experiments for reasons not clear to us, though this assignment is considered to be pertinent.

In the less epoxidized polymer, the $\mathrm{T}$ (E) $\mathrm{T}$ triad was remarkably predominant next to the $\mathrm{T}$ (T) $\mathrm{T}$ triad, and $\mathrm{C}_{1}-2, \mathrm{C}_{4}-1, \mathrm{C}_{5}-1$ signals could be assigned to the carbons in the epoxidized unit, ${ }^{1}$ (E), (E) ${ }^{4}$ and 5 (E), respectively, using the data in Figure 7. On the other hand, $C_{1}-3$ and $C_{4}-5$ signals could be assigned to the carbons in a trans-1,4 unit adjacent to an epoxidized unit, $\mathrm{E}^{1}\left(\mathrm{~T}\right.$ ) and $\mathrm{T}^{4} \mathrm{E}$, respectively. The intensities of the $\mathrm{C}_{1}-2$ and $\mathrm{C}_{4}-5$ signals are similar in the less epoxidized polymer, and this is also the same for the $\mathrm{C}_{1}-3$ and $\mathrm{C}_{4}-1$ signals. These correlations are considered strong evidence in 
Sequence Distribution in Epoxidized Polyisoprene

Table III. Signal intensities for olefinic carbons

\begin{tabular}{|c|c|c|c|c|c|c|}
\hline \multirow{3}{*}{ Signal $^{a}$} & \multicolumn{6}{|c|}{ Intensities $/ \%$} \\
\hline & \multicolumn{3}{|c|}{$\begin{array}{l}\text { Observed by } \\
\text { C-13 NMR }\end{array}$} & \multicolumn{3}{|c|}{$\begin{array}{l}\text { Calculated from } \\
\text { random assumption }\end{array}$} \\
\hline & $\begin{array}{l}\text { Sample } \\
\mathrm{a}\end{array}$ & $\underset{\mathrm{b}}{\text { Sample }}$ & $\begin{array}{l}\text { Sample } \\
\text { c }\end{array}$ & $\begin{array}{l}\text { Sample } \\
\text { a }\end{array}$ & $\underset{\mathrm{b}}{\text { Sample }}$ & $\begin{array}{l}\text { Sample } \\
\text { c }\end{array}$ \\
\hline \multicolumn{7}{|l|}{$\mathrm{C}_{2}$ carbon } \\
\hline $\mathrm{C}_{2}-1$ & 13.5 & 21.4 & 24.2 & 14.1 & 20.6 & 23.8 \\
\hline $\begin{array}{l}\mathrm{C}_{2}-2 \\
\mathrm{C}_{2}-3\end{array}$ & 70.1 & 58.5 & 51.9 & 71.8 & 58.8 & 52.4 \\
\hline $\mathrm{C}_{2}-4$ & 16.4 & 20.1 & 23.9 & 14.1 & 20.6 & 23.8 \\
\hline \multicolumn{7}{|l|}{$\mathrm{C}_{3}$ carbon } \\
\hline $\mathrm{C}_{3}-1$ & 14.6 & 20.6 & 23.7 & 14.1 & 20.6 & 23.8 \\
\hline $\mathrm{C}_{3}-2$ & 70.5 & 57.2 & 51.9 & 71.8 & 58.8 & 52.4 \\
\hline $\mathrm{C}_{3}-3$ & 14.9 & 22.2 & 24.4 & 14.1 & 20.6 & 23.8 \\
\hline
\end{tabular}

a The symbols are the same as in Figure 3. Signals are assigned in Table I.

b The degree of epoxidation was determined by ${ }^{1} \mathrm{H}$ NMR spectrum. Degree of epoxidation (\%): a, 17; b, $29 ; \mathrm{c}, 39$.

support of these assignments.

Variation in the chemical shifts of the epoxidized polymer with $39 \%$ epoxy content is indicated in Figure 8. The intensity of the pair signals $\mathrm{C}_{1}-4, \mathrm{C}_{1}-5$ and $\mathrm{C}_{4}-3, \mathrm{C}_{4}-4$, whose intensity ratios are similar and independent of the epoxy content of the polymer, increases with an increase in epoxy content. This suggests that these signals are related to the carbons in the epoxidized unit; these carbons are the $\mathrm{C}_{1}$ and $\mathrm{C}_{4}$ carbons of either the $\mathrm{E}$ (E) $\mathrm{T}$ or $\mathrm{T}$ (E) E triads. ${ }^{21}$ The assignment of these pair signals was confirmed by LSR experiments, although there was no remarkable difference in chemical shift variation.

There appeared five signals in each of the $\mathrm{C}_{1}$ and $\mathrm{C}_{4}$ methylene carbon regions in the spectrum and no relationship was found in their intensities between the two groups of the signals. The assignment of the methylene carbons in terms of the dyad or triad of trans-1,4 units and epoxidized units is summarized in Table II, which includes the assignment of the $\mathrm{C}_{5}$ carbons.

A more detailed observation of the ${ }^{13} \mathrm{C}$ NMR spectra showed that signals in the $\mathrm{C}_{2}$ carbon region split into some weak intensity peaks. These splits are thought to be caused by certain long range sequences and/or steric effects, and are remarkable when the polymer contains a great number of epoxidized units. But, the methyl carbon signals observed were insensitive to sequence distribution, and could be attributed only to the mono-ads of epoxidized or trans-1,4 units. It is not clear as yet as to why the neighbouring carbons $\mathrm{C}_{2}$ and $\mathrm{C}_{5}$ depend on the subsequent unit in a different manner. In some cases, especially concerning to the $\mathrm{C}_{5}$ and $\mathrm{C}_{2 \mathrm{E}}$ signals, each signal splits into a number of weak peaks by the addition of $\mathrm{Eu}(\mathrm{fod})_{3}$.

\section{Monomer Sequence Distribution}

Each monomer unit in these epoxidized polyisoprenes consists of five carbon atoms which give rise to different types of monomer sequences. This fact enables us to understand the monomer-unit sequence distribution of modified polymers if reliable quantitative analysis of ${ }^{13} \mathrm{C}$ NMR spectra is possible. Significant uncertainty in the quantitative analysis of proton-decoupled ${ }^{13} \mathrm{C}$ NMR spectra arises from different Nuclear Overhauser Enhancements (NOE). In the present study, however, this problem is not likely to be serious, because methyl $\left(\mathrm{C}_{5}\right)$, methylene $\left(\mathrm{C}_{1}, \mathrm{C}_{4}\right)$, and olefinic carbons $\left(\mathrm{C}_{2}, \mathrm{C}_{3}\right)$ are located in the same environment. Furthermore, we tried to make reliable quantitative analysis by operating the NMR apparatus at a rather long pulse-repitition time of $3.0 \mathrm{~s}$. 
Table IV. Signal intensities of methylene and methyl carbons

\begin{tabular}{|c|c|c|c|c|c|c|}
\hline \multirow{3}{*}{ Signal $^{\mathrm{a}}$} & \multicolumn{6}{|c|}{ Intensities $/ \%$} \\
\hline & \multicolumn{3}{|c|}{$\begin{array}{l}\text { Observed by } \\
\text { C-13 NMR }\end{array}$} & \multicolumn{3}{|c|}{$\begin{array}{l}\text { Calculated from } \\
\text { random assumption }\end{array}$} \\
\hline & $\begin{array}{c}\text { Sample } \\
\mathrm{a}\end{array}$ & $\underset{\mathrm{b}}{\text { Sample }}$ & $\begin{array}{l}\text { Sample } \\
\text { c }\end{array}$ & $\begin{array}{c}\text { Sample } \\
\mathrm{a}\end{array}$ & $\underset{b}{\text { Sample }}$ & $\begin{array}{l}\text { Sample } \\
\text { c }\end{array}$ \\
\hline \multicolumn{7}{|l|}{$\mathrm{C}_{1}$ carbon } \\
\hline$C_{1}-1$ & 67.8 & 51.2 & 35.7 & 68.9 & 50.4 & 37.2 \\
\hline$C_{1}-2$ & 14.0 & 18.5 & 21.6 & 12.2 & 17.1 & 20.4 \\
\hline$C_{1}-3$ & 13.2 & 22.2 & 27.2 & 14.1 & 20.6 & 23.8 \\
\hline$C_{1}-4$ & 2.5 & 4.0 & 8.2 & 2.4 & 6.0 & 9.3 \\
\hline$C_{1}-5$ & 2.6 & 4.1 & 7.3 & 2.4 & 6.0 & 9.3 \\
\hline \multicolumn{7}{|l|}{$\mathrm{C}_{4}$ carbon } \\
\hline $\mathrm{C}_{4}-1$ & 14.1 & 20.8 & 21.6 & 12.2 & 17.1 & 20.4 \\
\hline $\mathrm{C}_{4}-2$ & 70.9 & 49.4 & 35.5 & 68.9 & 50.4 & 37.2 \\
\hline $\mathrm{C}_{4}-3$ & 1.9 & 5.2 & 9.4 & 2.4 & 6.0 & 9.3 \\
\hline $\mathrm{C}_{4}-4$ & 2.0 & 5.2 & 9.1 & 2.4 & 6.0 & 9.3 \\
\hline $\mathrm{C}_{4}-5$ & 11.1 & 19.4 & 24.4 & 14.1 & 20.6 & 23.8 \\
\hline \multicolumn{7}{|l|}{$\mathrm{C}_{5}$ carbon } \\
\hline $\mathrm{C}_{5}-1$ & 18.3 & 29.5 & 37.5 & 17.0 & 29.0 & 39.0 \\
\hline $\mathrm{C}_{5}-2$ & 81.7 & 70.5 & 62.5 & 83.0 & 71.0 & 61.0 \\
\hline
\end{tabular}

a The symbols are the same as in Figure 4. Signals are assigned in Table II.

b The degree of epoxidation was determined by ${ }^{1} \mathrm{H}$ NMR spectrum. Degree of epoxidation (\%): a, 17: b, $29 ; \mathrm{c}, 39$.

The fractions of the triad sequences determined from the relative intensities in each carbon region are summarized in Tables III and IV, along with the theoretical sequences calculated on the assumption of random distribution in trans-1,4 and epoxidized units. Remarkable agreement between experimental and theoretical values supports not only the validity of the assignments but also that differences in the NOE factor and the effect of spin-lattice relaxation time of carbons may be overlooked.

These assumptions can be justified in various ways. The populations of $E(T) T$ are equal to those of $T$ (TE: the fractions of $E^{2}(T) T$ and $E\left(T^{3} T\right.$ are equal to those of $\mathrm{T}^{2} \mathrm{~T} \mathrm{E}$ and $\mathrm{T}\left(\mathrm{T}^{3} \mathrm{E}\right.$, respectively.

A random distribution of trans-1,4 and epoxidized units found by spectroscopical work explains why the epoxy groups introduced into polymers do not control the reaction site where a new epoxy group can be formed.

We previously observed the same situation in the epoxidation of polybutadienes. ${ }^{21}$ It is interesting that methyl groups which account for the structural difference between polybutadiene and polyisoprene do not affect the unit sequence distribution of the epoxidized polymers at all.

In this paper, we do not refer to those signals assigned to the epoxy carbons and the multiplicity in the $\mathrm{C}_{2}$ carbon in detail. However, it may be expected that futher study on the ${ }^{13} \mathrm{C}$ NMR of epoxidized polyisoprenes will make clearer both the epoxy configuration and long-range sequences.

The results of this investigation show that carbon13 NMR spectroscopy affords an extremely sensitive means for studying the reaction site and the monomer-unit sequence distribution of modified polymers.

Acknowledgement. The authors wish to express their sincere appreciation to Mr. Keiichiro Kimura and Dr. Shigeru Ikai, Ube Industries, for their helpful discussion. We are also very grateful to $\mathrm{Mr}$. Yasumitsu Ooi, Ube Industries, for his measurement of the NMR spectra. 


\section{REFERENCES}

1. M. W. Duch and D. M. Grant, Macromolecules, 3, 165 (1970).

2. Y. Araki, T. Yoshimoto, M. Imanari, and $\mathbf{M}$. Takeuchi, Kobunshi Kagaku, 29, 397 (1972).

3. J. Furukawa, E. Kobayashi, T. Kawagoe, N. Katsuki, and M. Imanari, J. Polym. Sci., Polym. Lett. Ed., 11, 239 (1973).

4. J. C. Randall, "Polymer Sequence Determination, Carbon-13 NMR Method," Academic Press, New York, N.Y., 1977.

5. J. Furukawa, E. Kobayashi, N. Katsuki, and T. Kawagoe, Makromol. Chem., 175, 237 (1974).

6. A. D. H. Clague, J. A. M. van Broekhoven, and L. P. Blaauw, Macromolecules, 7, 348 (1974).

7. Y. Tanaka, H. Sato, M. Ogawa, K. Hatada, and Y. Terawaki, J. Polym. Sci., Polym. Lett. Ed., 12, 369 (1974).

8. Y. Tanaka, H. Sato, K. Hatada, Y. Terawaki, and H. Okuda, Makromol. Chem., 178, 1823 (1977).

9. A. R. Katritzky and D. E. Weiss, J. Chem. Soc., Perkin Trans. 2, 1542 (1974).

10. Y. Tanaka, H. Sato, A. Ogura, and I. Nagoya, $J$. Polym. Sci., Polym. Chem. Ed., 14, 73 (1976).

11. Y. Tanaka, H. Sato, and T. Seimiya, Polym. J., 7, 264 (1975).

12. Y. Tanaka and H. Sato, Polymer, 17, 413 (1976).

13. H. Sato, A. Ono, and Y. Tanaka, Polymer, 18, 580 (1977).

14. W. Gronski, N. Murayama, H. J. Cantow, and T. Miyamoto, Polymer, 17, 358 (1976).

15. Y. Tanaka and H. Sato, Polymer, 17, 113 (1976).
16. G. G. Cameron, S. A. A. Chishti, J. R. Ebdon, and F. Heatley, Eur. Polym. J., 15, 203 (1979).

17. Y. A. Shahab and R. A. Basheer, J. Polym. Sci., Polym. Chem. Ed., 17, 919 (1979).

18. J. C. Randall, J. Polym. Sci., Polym. Phys. Ed., 13, 901 (1975).

19. R. V. Gemmer and M. A. Golub, J. Polym. Sci., Polym. Chem. Ed., 16, 2985 (1978).

20. O. Hayashi, T. Takahashi, H. Kurihara, and H. Ueno, Kobunshi Ronbunshu, 37, 195 (1980).

21. O. Hayashi, K. Kimura, Y. Ooi, and H. Ueno, Kobunshi Ronbunshu, 37, 327 (1980).

22. O. Hayashi and $\mathrm{H}$. Ueno, unpublished results.

23. I. A. Tutorskii, I. D. Khodzhaeva, and B. A. Dogadkin, Khim. Khim. Tekhnol., Tr. Yubileinoi Konf., Posvyashch. 70-Letiyu Inst., 187 (1970); Chem. Abstr., 81, 106968j (1974).

24. F. P. Greenspan, "Chemical Reactions of Polymers," E. M. Fettes, Ed., Wiley-Interscience, New York, N.Y., 1964, p 152.

25. K. Udipi, J. Appl. Polym. Sci., 23, 3301 (1979).

26. D. Swern, G. N. Billen, T. W. Findley, and J. T. Scanlan, J. Am. Chem. Soc., 68, 1504 (1946).

27. C. E. Wheelock., Ind. Eng. Chem., 50, 299 (1958)

28. D. Swern, "Organic Peroxides," Vol. II, WileyInterscience, New York, N.Y., p 466.

29. D. Swern, J. Am. Chem. Soc., 70, 1235 (1948).

30. L. P. Witnauer and D. Swern, J. Am. Chem. Soc., 72, 3364 (1950).

31. A. F. Cockerill, G. L. O. Davies, R. C. Harden, and D. M. Rackham, Chem. Rev., 73, 553 (1973).

32. M. R. Willcott, J. F. M. Oth, J. Thio, G. Plinke, and G. Schröder, Tetrahedron Lett., 1579 (1971). 